\title{
A Functional Contextualist Account of Behavioral Economics: Relational Frame Theory Applied to Decision-Making and Choice Behavior
}

\author{
Uma Abordagem Funcional Contextualista da Economia Comportamental: \\ Teoria das Molduras Relacionais Aplicada à Tomadas de Decisão e \\ Comportamentos de Escolha
}

\author{
Un Enfoque Funcional Contextualista de la Economía del Comportamiento: \\ Teoría de los marcos relacionales Aplicada a la Tomas de Decisión y las \\ Conductas de Elección
}

\author{
Marco Tagliabue $^{1}$, Massimo Cesareo $^{2}$, Valeria Squatrito ${ }^{3}$, Giovambattista Presti ${ }^{3}$
}

\begin{abstract}
[1] Department of Behavioural Sciences, Faculty of Health Sciences, OsloMet - Oslo Metropolitan University, Oslo, Norway [2] IESCUM - Istituto Europeo per lo Studio del Comportamento Umano - Parma, Italy [3] Kore University Behavioral Lab, Department of Human and Social Sciences, Kore University, Enna, Italy I Título abreviado: Behavioral Economics and Relational Frame Theory I Endereço para correspondência: Marco Tagliabue, PB 4 St. Olavs plass, N-0130 Oslo, Norway I Email: marco.tagliabue@oslomet.no I doi: 10.18761/PAC.2021.v12.RFT.05
\end{abstract}

\begin{abstract}
Behavioral economics is a discipline that is mainly rooted in cognitivism and that is concerned with the study of decision-making processes and choice behavior. These involve addressing the relations between cognition and overt behavior, which comprise one of the most challenging topics in the domain of behavioral sciences at large and have been approached by different epistemological viewpoints. Within the cognitivist tradition, private events have been often treated as causes of behaviors, adopting a mechanistic view. Conversely, a contextual functional behavioral perspective treats them with the same methodology that is adopted for overt behaviors. Relational frame theory, a post-Skinnerian theory of language and cognition, offers a behavioral perspective on cognition and overt behavior and how they influence human behavior, by keeping a high degree of coherence with basic principles and goals of behavior analysis (i.e., effective action). This conceptual paper represents an attempt to offer a perspective drawn from contextual behavioral science on some constructs described in behavioral economics. Furthermore, it provides a common ground for behavior analysts and researchers in other fields of psychology to further expand our knowledge and respective explanations of decisionmaking processes. Finally, it draws a line for connecting basic research to applied solutions.
\end{abstract}

Keywords: Relational frame theory, behavioral economics, decision-making, cognition, value. 
Resumo: Economia comportamental é uma disciplina fundamentada principalmente no cognitivismo e dedica-se ao estudo de processos de tomada de decisões e comportamentos de escolha. Ambos envolvem a abordagem de relações entre cognição e comportamento manifesto, que compreende um dos tópicos mais desafiadores no domínio das ciências do comportamento. Diferentes perspectivas epistemológicas orientam a abordagem aos fenômenos. A partir de uma tradição cognitivista, eventos privados têm sido tratados frequentemente como causas de comportamentos, adotando uma visão mecanicista. Contrariamente, uma perspectiva comportamental funcional e contextual os aborda com a mesma metodologia adotada para comportamentos manifestos. A teoria das molduras relacionais, uma teoria pós-Skinneriana da linguagem e da cognição, oferece uma perspectica comportamental sobre o papel e a influência da cognição sobre o comportamento humano, mantendo alto grau de coerência com princípios básicos e objetivos da Análise do Comportamento (i.e., ação efetiva). O presente trabalho conceitual representa um esforço para apresentar explicações extraídas da ciência comportamental contextual a respeito de alguns conceitos descritos pela economia comportamental. Além disso, propõe uma base comum para analistas do comportamento e pesquisadores de outras abordagens da Psicologia que contribua com a expansão do conhecimento e explicações acerca de processos de tomada de decisão. Traça-se uma linha de conexão entre a pesquisa básica a soluções aplicadas.

Palavras-chave: Teoria das molduras relacionais, economia comportamental, tomada de decisões, cognição, valor.

Resumen: La economía comportamental es una disciplina radicada en el cognitivismo y que trata el estudio de los procesos de toma de decisiones y comportamientos de elección. Ambos involucran el estudio de relaciones entre cognición y comportamiento manifiesto, lo cual incluye algunos de los temas más desafiantes en el dominio de las ciencias comportamentales y que ya han sido tratados desde diferentes puntos de vista epistemológicos. A lo largo de la tradición cognitivista, los eventos privados han sido a menudo tratados como causas de comportamientos, utilizando una mirada mecanicista. En cambio, una perspectiva comportamental funcional y contextual los trata con la misma metodología que viene adoptada para comportamientos manifiestos. La teoría de los marcos relacionales, una teoría post-Skinneriana del lenguaje y de la cognición, ofrece una perspectiva comportamental sobre cognición y comportamientos manifiestos y como ellos influencian el comportamiento humano, manteniendo un alto nivel de coherencia con los principios básicos y objetivos del análisis comportamental (i.e., acción efectiva). Este articulo conceptual representa un intento de ofrecer una perspectiva extraída desde la ciencia comportamental contextual sobre algunos constructos descritos en economía comportamental. Además, proporciona una base común para analistas del comportamiento y investigadores en otros campos de la psicología para expandir ulteriormente nuestro conocimiento y las explicaciones correspondientes sobre los procesos de tomas de decisión. Por último, traza una línea de conexión entre investigación de base y soluciones aplicadas.

Palabras clave: Teoría de marcos relacionales, economía comportamental, toma de decisiones, cognición, valor. 
Relational frame theory (RFT) is a post-Skinnerian account of language and cognition. These are conceptualized as a particular type of operant behavior, named arbitrary applicable relational responding (AARR). The explanatory power of RFT extends principles of behavior analysis (BA) to the domain of higher cognitive functions and addresses non-direct (i.e., derived) learning and value-based behavioral change. Moreover, RFT explains how humans equally assign values to objects, events and experiences; it offers an alternative account of how the tradition of behavioral economics (BE) values commodities.

$\mathrm{BE}$ can be defined in its most simple form as "economics with more explanatory power because the models are a better fit with the data" (Thaler, 2016, p. 23). It stems from the descriptive inadequacy of the standard economic model to account for systematic deviations from "best" decisions: that is, decisions that grant the highest utility or reinforcement. Quiñones, Hayes, and Hayes (2000) maintained that RFT was positioned well enough as an account of human language for providing a needed corrective in the analysis of complex consumer behavior and, more general, to psychology. As the consequences of actions are not always conveyed contingently, an analysis of verbal behavior may identify rules that may put in touch an individual with the description of contingencies, without necessarily experiencing them directly. Embracing an RFT approach may allow us to be more precise insofar as the understanding of the functional relation between verbal antecedents and human behavior is concerned, especially when consequences are possibly delayed, uncertain or abstract.

Although BE and BA share a tendency to provide descriptive accounts of behavioral patterns (i.e., describing how individuals act in the presence of certain stimuli), there is at least one difference concerning the way in which cognition is treated. In fact, behavioral economists often tend to appeal to what they term as biases in order to describe cognitive mechanisms that lead people to act in a way that is not in line with the notion of rationality (i.e., maximizing or optimizing outcomes). That implies a causal relation between cognition and (overt) behavior. Although the use of the term bias (as well as other mentalistic terms adopted in BE), may have a heuristic function, from a behavior analytic perspective it should not take on an explicative function, for this would hinder the possibility to influence it (Cesareo, 2018). Conversely, by adopting a behavioral analytic standpoint, our attention goes herein to describing what a bias is and what are the contextual variables of its occurrence.

In order to meet the utility criteria (successful manipulation) of a context-based approach, we should start addressing the external contingencies that can be manipulated to understand what a bias is. Next, we may prevent and overcome the occurrence of a bias as long as it is aimed at improving the human condition. In other words, we need to identify relevant contextual variables to improve our understanding and influence of behavior. As stated by Skinner (1974): "Explaining behaviors using mental states, just move(s) the focus out of the research of (an explanation of) the behaviors. (To) Rely upon an "inner person" means to give an explanation (of) to something that could not be explained (itself and its just a way to explain things that we are not able to explain) in other ways" (p. 165).

The first aim of this paper is to extend a functional contextual approach resting on BA to other fields than those traditionally explored, widening its application, and calling for forthcoming applicative studies from other areas, including but not limited to the field of BE. We drive analogies from RFT and acceptance and commitment therapy (ACT; i.e., a research-based intervention derived from RFT) based on studies and research protocols that have been implemented in the field of organizational behavior management (see Hayes, Bond, Barnes-Holmes, \& Austin, 2006). Similarly, we are interested in showing how RFT can expand the behavior analytic root of the field of BE, which has attracted researchers with diverse backgrounds (e.g., psychology, economics, marketing, law, etc.). BE has been traditionally influenced to a much larger extent by a cognitive vision than an approach grounded on a scientific analysis of behavior (interestingly enough so, for the former is electively considered a behavioral science, but the latter is reluctantly so) (see Carr, Luke, \& Arntzen, 2019). Nevertheless, there have been cases in which the functional and cognitive views might "collaborate" (see De Houwer \& Hughes, 2019, 2020; De Houwer, Hughes, \& Barnes-Holmes, 2017a, 2017b). 
The second aim of this conceptual work is twofold. First, we offer common grounds for both behavior analysts and other researchers in the field of psychology to come together and expand further the field by blurring the line between basic research and applied solutions. We present RFT as a theory that integrates and extends behavior analytic principles to include human cognition. Specifically, we target choice behavior insofar as both its conceptual explanations and applied implications are concerned. In this context, we refer to choice not by limiting its meaning to economic decision making, but rather extending it to any behavioral direction that a human being follows as a function of antecedents, consequences, and learning history. However, when dealing with symbolic behavior, it is necessary to take into consideration the important component that comes from derived learning: this is, learning without any direct contact with contingencies, which may also lead to a bias. We start by introducing the broader objective of RFT to account for human cognition and we set out to understand how RFT and BE address verbal behavior. Specifically, we focus on the concepts of bias, discounting, and value. Lastly, we discuss applied implications and a tool for putting to empirical test some of the concepts raised in the next sections.

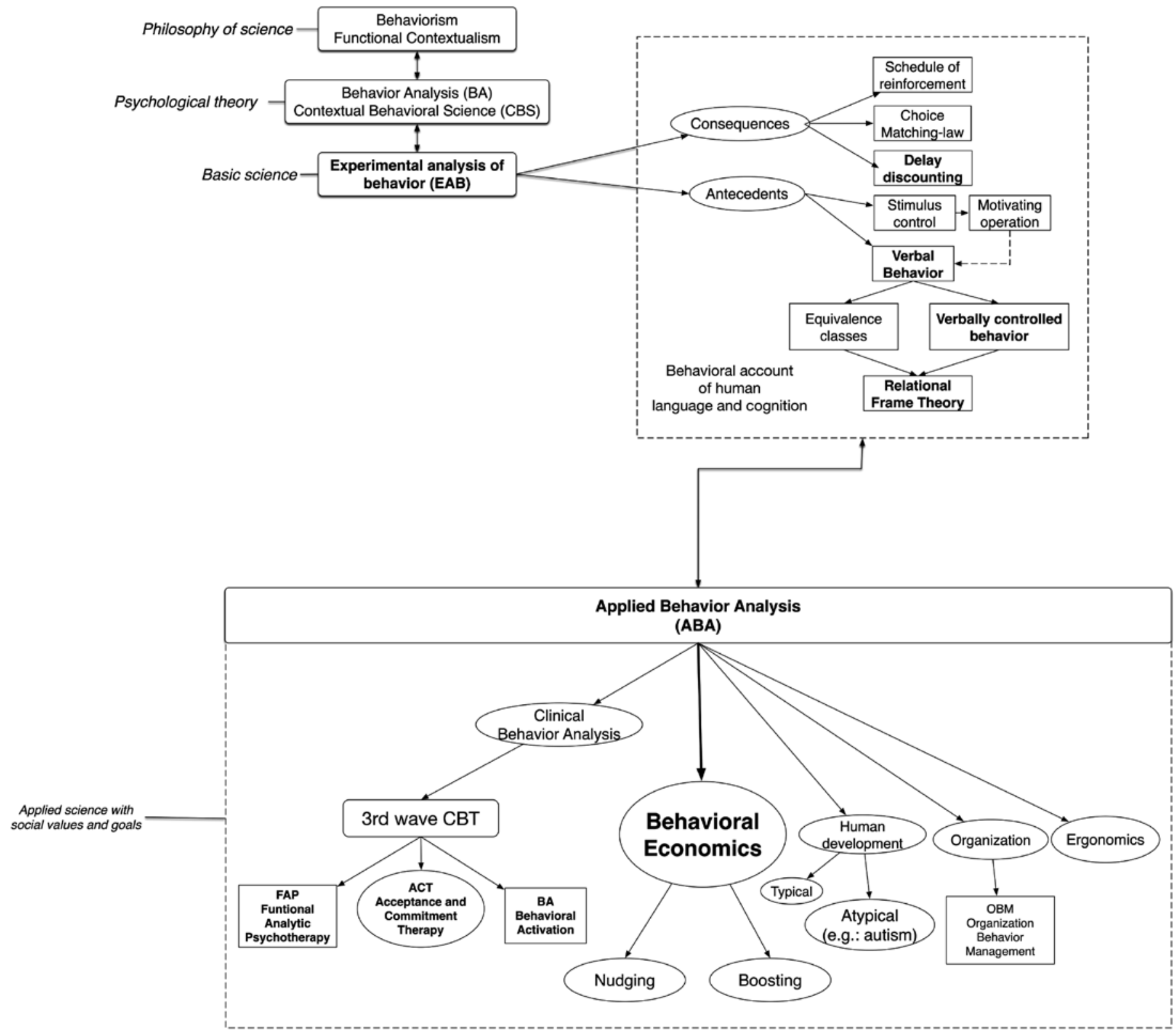

Figure 1. Diagram of relations between a behavioral account of human language and cognition and basic and applied science. 
The vision herein described assumes that $\mathrm{BE}$ could be seen as an applied field within applied behavior analysis. Similar to other areas of application that span from education, to organization and clinical applications, important benefits may be drawn from basic research studies coming from the experimental analysis of behavior (EAB). Figure 1 represents our take on the interconnections that a behavioral account of human behavior, including language and cognition, has with basic and applied science, respectively. Although it may be perceived as an oversimplification of the interconnections between different areas of basic and applied behavioral analytic studies, the point is to offer a sense of how the conceptualization of $\mathrm{BE}$ within a behavioral framework may put basic and applied researchers in a position to better understand and manipulate the environmental variables (i.e., basic, or top-down), and policy makers and governmental agencies to adopt better and long-term solutions to create socially relevant impact (i.e., applied, or bottom-up). In addition, it fosters collaboration and integration from different fields within applied behavior analysis, which shares with $\mathrm{BE}$ a common goal of striving for an increased explanatory power of (economic, organizational, abnormal, etc.) behavior. While BE strives to "generating theoretical insights, making better predictions of field phenomena, and suggesting better policy" (Camerer, Loewenstein, \& Rabin, 2004, p. 3), we argue that BE and BA could and should jointly inform and shape social policies and phenomena for the better. If we consider language and cognition as behaviors, it is easier to think of interventions that manipulate the context for improving our condition. In the same way, it will be easier to observe the links between $\mathrm{BA}, \mathrm{BE}$, and possibly education and psychotherapy.

\section{Relational Frame Theory Extends the Behavior Analytic Vision to Cognition}

Two main scientific goals of BA are prediction and control of behavior. In order to pursue the latter, behavior must be explained by considering contingencies that lie in the environment. Whenever dealing with overt or covert behavior, a behavior- behavior relation is considered incomplete and needs be further analyzed. On this extent, several of the topics of BA share with mentalistic accounts the same potentially "metatheoretical problems" of encouraging incomplete accounts (Hayes \& Brownstein, 1986). For example, one of them is the nature of the relation between covert and overt behaviors. Questions such as "What role does thinking play in the control of behavior?" are focusing on the nature of a behavior-behavior relation that must be explained by appealing to particular contextual arrangements (Hayes \& Brownstein, 1986).

Assuming that there is a causative relation between thoughts and overt behaviors could be a complete explanation to the mechanist, whose view of the world does not insist on influence as a necessary goal of science, and whose truth criterion is not usefulness within a model, but coherence as in a mechanistic one (Hayes \& Brownstein, 1986). However, for those assuming a functional contextualistic position, like behavior analysts, that would not be sufficient. As Skinner (1974) noted, once we have explained a response by appealing to mentalistic terms, we still need to explain their origins and be able to manipulate the functional relation with the behavior. This raises a difficult challenge in BA: namely, how is it possible to provide a comprehensive account of the relation that occurs between covert and overt behaviors while avoiding appealing to tautological explanations? As Hayes, BarnesHolmes and Roche (2001) stated, "[t]he analysis of human language remains a mountain that behavioral psychology has yet to climb" (p. 19).

The relation covert-overt behavior is relevant in several areas: among them is BE, where today the behavior analytic vision is overshadowed by the cognitive tradition. Whereas, historically, the $\mathrm{BE}$ tradition was partially characterized by a behavioral approach, similar to Brandon (2008), we maintain that behavior analysis and contextual behavior science may enhance our understanding of behavior change within the scope of BE: this includes choice, decision-making, judgement, and the extent to which biases and values may affect them. Nevertheless, this approach does not program for neglecting the cognitive processes underlying their resulting behavioral outputs; rather, it puts forward an integrated model informed by RFT to increase 
the explanatory and predictive power of the behavioral assumptions on which $\mathrm{BE}$ experimentation has focused ever since the tenets of bounded rationality were set (Simon, 1955). Bounded rationality refers to the concept apt to capture and describe how the limits in our thinking capacity, available information, and time (Simon, 1983) can exert a systematic influence on our decisions. In other words, we propose a cognitive and behavioral model that has the potential to enhance the field: it extends the cognitive focus of BE by providing a more technical analysis of behavior (e.g., choice, decision-making, etc.) and it deepens the explanation and prediction of behavior by putting the analysis of cognitive processing back into the picture.

\section{Language and Cognition: A Contextual Behavioral Vision}

RFT conceptualizes language and cognition as being constituted by a specific high order pattern of operant behavior, which is termed arbitrary applicable relational responding (AARR). AARR is functionally characterized by derived responding (mutual and combinatorial entailment) and transformation of stimulus function. Verbally competent human beings progressively learn to respond to more and more articulated networks of mutual relations. These relations start from coordination and expand to opposition, temporal, spatial, distinction, deictic, and others when a human being develops language. Contextual cues control the type of relations to which we respond to. RFT recognizes that frames are involved in creativity, problem solving, IQ, prejudice and other human activities. Thus, language is the set of symbols that we use, manipulate, react to, and act upon. Language includes not only words, but also images, sounds, facial expressions, and gestures. Moreover, we can make public or private use of language.

Studying how symbolic behavior is manipulated and how we respond to it represents the core of RFT research. Derived relational responding allows us to learn without the need for direct experience. Research suggests that the same tools we use to solve everyday problems can confine us in the quicksand of suffering. The same arbitrary relational patterns related to "normal" functioning are implied in "dysfunctional" behaviors (Hayes,
Barnes-Holmes, \& Roche, 2001). For example, after learning one of the most common type of relations, if...then, which is necessary for planning, we might start predicting events in the future; next, we can react to those predictions and act to emotions we feel in the present and their derived scenarios. While the event has not yet occurred, we can feel anxious or fearful, safe or firm when making that prediction. Similarly, by building comparative and evaluative relationships, which are needed in problem solving to evaluate and compare, we can compare ourselves with an ideal situation, person or self and feel confident or inadequate. We can perceive ourselves qualified or inferior to others or fear the judgment of ourselves or others even in the absence of such a direct experience (see also Hayes, Strosahl, \& Wilson, 2012).

From this point of view, there are no functional or dysfunctional behavioral patterns. That is to say that all patterns are functional in the sense that they are a function of the environmental variables that control them. Even in worst-case scenarios, where an individual's prediction of a failure on a future occasion increases the probability of emitting an avoidance pattern, this pattern is always under the control of environmental events. For example, if a child exhibits patterns of behavior that have been clinically described as "social phobia", these patterns might be a function of avoidance and under the control of verbal antecedents related to the anticipation of disastrous social interactions. Likewise, patterns of actions that are under the control of verbal antecedents such as "I need to invest in this cryptocurrency before it is too late", might lead to relevant economic losses. Thus, RFT and ACT show that there are no dysfunctional patterns, and that the term dysfunction comes from deviating one's own life path from one's valued direction. In the previous example, the sociophobe child may have friends and social relations instead of avoiding the predicted dreadful consequences that may arise from them. In the second, fusion with thoughts and avoidance of discomfort related to loss of hypothetical gains might, in fact, bring to worse economic consequences.

A misconception that is shared by several critics preaches that BA ignores consciousness, feelings, and states of mind; thus, it poses limits to its appli- 
cations (Jensen \& Burgess, 1997; Puligandla, 1974; Todd \& Morris, 1983). Although behavior analytic accounts have been accused of neglecting cognitive processes, RFT emerged as an evidence-based account of language and cognition that sought to expand Skinner's vision into a new theory, by providing a useful framework to better understand the core characteristics of language.

The early origins of RFT trace back to 1985 , to a paper in which Hayes and Brownstein (1985) were trying to offer an alternative and broader picture to the one that was emerging from the early studies on stimulus equivalence (Palmer, 2004). Since then, an increasing number of studies have been published to account for the verbal processes underlying the typically human feature of sense making and knowing (Bordieri, Kellum, Wilson, \& Whiteman, 2016). This account of symbolic behavior has been applied to several fields and its concepts are in constant development (Barnes-Holmes, Barnes-Holmes, Luciano, \& McEnteggart, 2017; see also BarnesHolmes, Barnes-Holmes, \& McEnteggart, 2020). While several contributions have widened the horizons of the initial formulations (Hayes, BarnesHolmes, \& Roche, 2001) and are still in need of empirical support, RFT is empirically robust enough (Dymond, May, Munnelly, \& Hoon, 2010; O'Connor, Farrell, Munnelly, \& McHugh, 2017) to offer a coherent picture of both overt (language), and covert (cognition) human symbolic behavior.

\section{The Analysis of Behavior and Cognition in the Behavioral Economics Domain}

A cognitive bias is thought as a behavioral pattern deviating from a norm or rationality in judgment as a consequence of subjective reality created from an individual's perception of inputs from the world. Several systematic cognitive distortions have been associated with the notion of bias; they have been identified, studied, and described over the past decades, thanks to the development of several research programs (e.g., Tversky \& Kahneman, 1974). Departing from the concept of bounded rationality (Simon, 1955, 1972), it is possible to trace a continuum to explain irrational behaviors (Reed,
Niileksela, \& Kaplan, 2013), which are deviations from best or optimal choices and decision making insofar as their subjective value is concerned (i.e., utility). According to the cognitive psychology tradition, irrational behaviors have been described in terms of mentalistic psychological causes, such as cognitive biases or psychological predispositions (e.g., Angner \& Loewenstein, 2007; Camerer, 1999; Kahneman, Slovic, \& Tversky, 1982). However, the BA perspective tended to focus on behavioral principles as a useful tool to define irrational behaviors (e.g., Hursh, 1980; Skinner, 1953).

Smets (2018) highlighted that following the widespread tendency to interpret biases as entities capable to explain or to cause behavior could lead to several issues. According to BA, the adoption of this standpoint for examining if and how deviations from optimal (i.e., rational) decision making does not seem enough. Invoking a bias as the cause of a behavior is a tautology. Thus, we would be prone to explain why we behave in a certain way by blaming the effects of an underlying bias. Furthermore, when asked to explain what a bias is, the answer would be behaving in a certain (irrational) way, which then brings us back to the previous question. In sum, the relation between context and behavior becomes fundamental. Moreover, irrational behaviors may be regarded as the result of the reinforcing actions provided by the context towards establishing negative consequences (e.g., overeating, smoking, lack of physical activity, etc.): in this sense, they are dysfunctional. This type of dysfunctional relations between behaviors and consequences were defined by behavioral economists as the reinforcer pathology model: that is, pathological patterns of responding for differentially valued reinforcers. Similar to a proposed approach for understanding and treating addiction, we attempt to provide an explanation of irrational behaviors that does not need to invoke mentalistic constructs (Bickel, Jarmolowicz, Mueller, \& Gatchalian, 2011).

Baumeister (2001) described three broad classes of consequences to which irrationally may lead: deliberate self-harm, trade-offs, and counterproductive strategies. Self-destruction and self-handicapping are examples of the first class, which is featured by a deliberate effort to annihilate oneself, or nonetheless lowering one's future 
performance for self-interest. The student partying until late the night before an exam is due is a typical example of self-handicapping behavior (see Wilkinson, 2008). This behavior may be interpreted as overconfidence, lack of self-esteem or self-regulation, which comprise dispositional factors. However, it may also be interpreted by situational factors, such as the unimportance of the exam, the opportunity of social encounters, an attempt to personal gratification, or an avoidance pattern to manage stressing sensations coming from overtly or covertly talking about the exam. As far as an analysis of behavior is concerned, the student may be said to be impulsive, in the sense that he or she prefers the immediate, certain, and "stronger" reinforcement of the party than the delayed, uncertain, and "weaker" reinforcement of possibly passing the exam. Thus, BA can offer a more parsimonious account of irrationality compared to other approaches, and "does not require abstract theoretical explanations that are difficult to empirically evaluate and observe" (Reed et al., 2013 , p. 36). The next section addresses this topic, considering choice and an experimental procedure to measure choice.

The second class of consequences of irrationality are trade-offs, which occur in the presence of inconsistent intertemporal choice with one own's preferences. This may lead to the phenomenon of discounting values, which may affect not only temporal outcomes, but also probabilistic (or a combination of the two: both temporal and probabilistic) and social outcomes (see Jones \& Rachlin, 2006). We take up the analysis of delay discounting from a rounder approach that includes both outcomes and processes.

Lastly, we discuss the third class of consequences of irrationality: counterproductive strategies. These are displays of perception errors that misguide self-interested strategies; in other words, they are comprise patterns of lack of self-control, such as in the case of the alcoholic. We will relate all these issues referring to the conceptualization of cognition that RFT offers, focusing particularly on values and their role in $\mathrm{BE}$ and RFT.

\section{Hindering Change in Cognitive Terms: Definition and Role of Biases}

Mentalistic elements have often been excluded in a behaviorist account of human activity, not necessarily because they are denied or call outside the scope of analysis, but rather due to the impossibility to manipulate them directly; thus, because they are unnecessary to pursue the goal to control behavior (Skinner, 1953). However, language, thoughts, judgements, and choices are all behavior. This statement may appear simplistic to those outside the behavioral analytic community, but from a functional point of view there might be no differences between implicit and explicit topographies (for a more detailed explanation on this topic, see Barnes-Holmes, Barnes-Holmes, Stewart, \& Boles, 2010), insofar as their sources, antecedent, and consequences are concerned. In BA, antecedents include two main classes of stimuli: the first is a discriminative stimulus $\left(S^{D}\right)$ and the second is a motivating operation (MO). A stimulus, object, or event has a discriminative function when it sets the occasion for a certain behavior to occur. An MO changes how much you "want" something and how hard you will "work" to get it (Michael, 1982, in Langthorne \& McGill, 2009). In other words, it changes the value of consequences and the rate of occurrence of the related behavior (see Gomes et al., 2020 on alternating the transformation of function using motivational conditions).

From an economist's point of view, BE challenges the traditional assumptions of economic theory, according to which our decisions are conceptualized as being perfectly rational. Notwithstanding, direct experience and a wide body of empirical research have (disappointingly) demonstrated the contrary. Kahneman (2003a, 2011) proposed to adopt a dual system model to describe how decisions are taken. In order to make a clear distinction between intuitive and analytical reasoning, the author borrowed from Stanovich and West (2000) two metaphorical terms: System 1 and System 2. The former has been described as fast, automatic, effortless, associative, and difficult to control. Conversely, the latter is slower, serial, effortful, and deliberately controlled. RFT analyzes higher cognitive functioning and extends the set of operant principles typical 
of BA. When applied to a dual-process cognitive theory (Kahneman, 2003a), it accounts for the rapid intuitive judgment encompassed in System 1 and the conscious awareness (i.e., analytic thinking) of System 2, that are evoked by cognitive permeated analyses in BE (for an alternative account, see also Hughes \& Barnes-Homes, 2013).

According to Kahneman's vision, in most situations the two systems would act in coordination. However, this is not always the case and, as a result, predictable distortions may occur, which are termed biases. A bias can be described as a systematic mistake in decision making, that occurs in specific circumstances: for example, resulting from the conflicting processes between these two systems (Kahneman, 2011). It is normatively regarded as an obstacle to optimal decision making and, thus, should be avoided or corrected as much as possible. Some behavioral economists proposed to embrace an evolutionary perspective in order to better understand the process of decision making (e.g., Gigerenzer, Hertwig, \& Pachur, 2011; Gigerenzer, Todd \& ABC Research Group, 1999). From this perspective, heuristics (i.e., rules of thumb) are regarded as behavioral responses that evolved over time, according to the constraints of the environment and the organism. It is thus necessary to analyze the structure of the specific environment in which a behavior takes place in order to understand under which conditions resorting to heuristics is likely to fail or succeed (Goldstein \& Gigerenzer, 2002). The extent of matching heuristics with a specific context can possibly determine their accuracy and, thus, the occurrence of bias. In behaviorist words, the context influences the way we respond to overt or covert verbal antecedents.

Some of these assumptions are consistent with the views of $\mathrm{BA}$, according to which a bias may be described as a behavioral pattern that has been selected over time due to a history of interaction with certain reinforcing contingencies (i.e., the learning history). This seems to hold true both at the phylogenetic and ontogenetic levels. It is also important to emphasize that previous stimuli can exert control on behavior and may be of a physical or verbal/ symbolic nature. One can substantially distinguish in this sense between behavior shaped by contin- gencies and behavior governed by verbal rules. In the first case, behavior is shaped and maintained by stimuli that lay in the physical context. In the second case, it is controlled by verbal antecedents: rules enunciated by others or through verbal processes of derivation and transformation of stimulus function (Catania, 1995; Catania, Shimoff, \& Matthews, 1989; Zettle \& Hayes, 1982). Thus, when considering the learning history, we should take into account not only the history of individuals' interaction with their physical environment, but also with their verbal community. Once behaviors are governed by verbal rules, they tend to become relatively insensitive to direct contingencies; particularly those repertoires that have been acquired under the control of socially mediated reinforcement for coordination between behavior and antecedent verbal stimuli. It follows that certain behaviors may tend to be repeated, even when the context changes and alternative responses would be more adaptive and reinforced by direct contingencies.

Stepping from the consideration of rules as contingency-specifying verbal behavior (i.e., stimuli specifying consequences; Skinner, 1966), three types of rule-governed behavioral patterns can be thus identified: pliance, tracking, and augmenting. Pliance is a "rule governed behavior under the control of apparent socially mediated consequences for a correspondence between the rule and relevant behavior" (Hayes, Zettle, \& Rosenfarb, 2004, p. 203). Tracking is a "rule-governed behavior under the control of the apparent correspondence between the rule and the way the world is arranged" (Hayes et al., 2004, p. 206). Finally, augmenting is defined as "rule-governed behavior under the control of apparent changes in the capacity of events to function as reinforcers or punishers" (Hayes et al., 2004, p. 206).

\section{Verbal Behavior as an Antecedent: Contingencies and Rules}

We learn directly from experience (contingencyshaped behavior) and from relating stimuli to one another (derived relational responding). RFT researchers have shown that we respond to numerous relations between events under the control of contextual stimuli, that are called frames and include difference, oppositeness, comparison, if...then, before...after, more...less, and perspective. Derived 
relational responding (Barnes-Holmes, BarnesHolmes, Roche, \& Smeets, 2001a, 2001b; Campbell, Barnes-Holmes, Barnes-Holmes, \& Stewart, 2011; Whelan, Barnes-Holmes, \& Dymond, 2006) is a class of context-sensitive and context-driven responses, which are learned through repeated exposure to multiple examples. They can relate stimuli in terms of physical (non-arbitrary applicable relational responding - NAARR) or symbolic characteristics (AARR). Moreover, RFT provides an explanation of how we respond to different verbal relations. Specifically, response patterns that have been reinforced more frequently or that are relationally coherent are likely to be emitted more rapidly (Barnes-Holmes et al., 2017). According to an RFT-based account of cognition called relational elaboration and coherence (REC) model, this type of derived relational responding is termed brief immediate relational responding (BIRR). It is characterized by low levels of derivation and complexity. Conversely, response patterns that have been reinforced with a lower frequency are likely to be emitted more slowly and may require more effort. In the latter case we speak of extended and elaborated relational responding (EERR), which features high levels of derivation and complexity (e.g., Barnes-Holmes et al., 2010; Barnes-Holmes, Murphy, Barnes-Holmes, \& Stewart, 2010; Hughes and Barnes-Holmes, 2013).

Nevertheless, the REC model does not take into account coherence (Barnes-Holmes et al., 2017) and flexibility (Barbero-Rubio, López-López, Luciano \& Eisenbeck, 2016; O'Toole \& BarnesHolmes, 2009), whereas BIRRs show a higher degree of coherence and EERR show a lower degree of coherence. In order to partially account for this limitation, Barnes-Holmes et al. (2017) proposed the multi-dimensional multi-level (MDML) model, which includes four functional properties (coherence, complexity, derivation and flexibility) and five levels of relational responses (mutual entailing, relational framing, relational networking, relating relations and relating relational networks). We can respond to relationships between stimuli that are not trained or not specifically learned (derivation), which may involve simple stimuli or stimuli involved in the relationship (complexity). Moreover, we can modify a relational response as a function of a contextual variable (flexibility), and we respond to new stimuli in a way that is consistent with what we learned previously (coherence). By increasing the level of complexity and flexibility of derived responses, we can respond to relations and relational networks (Barnes-Holmes et al., 2017). Together, the five levels of relational responses and the four properties previously defined can be combined to form a conceptual framework for analyzing the dynamics of AARR as an operant repertoire (BarnesHolmes et al., 2017).

Thus, RFT offers an experimental interpretation of insensitivity to the effects of social contingencies when verbally controlled behavior is at stake and is related to persistent patterns of non-functional behaviors (Hayes et al., 2001). Acting under the control of verbal antecedents is not always dysfunctional, especially when it leads to preventing dangers. However, it can be related to dysfunctional choices and habits inasmuch as some circumstances might also lead to mental disorders. In other circumstances, the symbolic context may influence the choice architecture and henceforth the behavior of an agent; for example, by contextual manipulation of antecedent terms, like the nudging approach. Tagliabue, Squatrito, and Presti (2019) have examined in more detail the commonalities and differences between Kahneman's dual-process vision and models of cognition resting on RFT, while offering an alternative conceptualization of Systems 1 and 2 based on relational responding.

In sum, a bias could be seen as response pattern that manifests itself as the result of an individual's learning history and shows a low degree of derivation, a high degree of coherence and a low one of flexibility (Hughes, Barnes-Holmes, \& Vahey, 2012). From an RFT point of view, a cognitive bias can be interpreted as a pattern of behavior determined by a reduced sensitivity to contingencies and inaccurate rules (Dixon, Hayes, \& Aban, 2000). It corresponds to the flexibility with which an individual can assert a specific attitude or its opposite (Vahey, Boles, \& Barnes-Holmes, 2010). RFT provides useful tools both for analyzing these behavioral repertoires (e.g., the implicit relational assessment procedure - IRAP), and to train agents to establish new relational and more flexible networks. These may enhance our ability to act in a way that 
is more adaptive to the ongoing contingencies (e.g. applying ACT-based clinical and non-clinical trainings; for a review, see Howell \& Passmore, 2019).

Without neglecting the contributions that BA and $\mathrm{BE}$ have made to our understanding of complex relations (e.g., Kahneman, 2003b; Reed et al., 2013; Sidman, 1994; Sidman \& Tailby, 1982; Tversky \& Kahneman, 1981), there are very few studies in which an RFT approach was clearly resorted to. For example, contributions from RFT have been used to account for cognitive biases and how they may lead to the problem of social categorization (Weinstein, Wilson, Drake, \& Kellum, 2008): the authors of that study used the implicit association test (IAT) to investigate "the transformation of stimulus functions from socially relevant to arbitrary stimuli as a model of social stigmatization and categorization" (p. 40). Specifically, they were able to condition bias functions to arbitrary stimuli by fluency-based training (see Heinicke, Carr, Leblanc, \& Severtson, 2010). Conversely, the IRAP is an experimental procedure for estimating relational acts based on latency between presentation of stimuli and response (BarnesHolmes et al., 2006). It positions itself separately from the IAT inasmuch as it can implicitly differentiates between beliefs that differ from one another pertaining their relational component (BarnesHolmes et al., 2010; De Houwer, Heider, Spruyt, Roets, \& Hughes, 2015).

\section{Delay Discounting and Choice Behavior}

In addition to rule governed repertoires that are under the control of socially-mediated consequences (pliancing), and those that are under the control of direct environmental contingencies produced by the behavior itself (tracking), there is another form of rule-governed behavior, which is controlled by verbal antecedents that alter the degree to which consequences function as reinforcers (augmentals). In less technical terms they are called values. Valuing has an enormous impact in verbally contacting stimulus functions that alter the present ones: for example, they may transform potentially punishing or neutral environments into reinforcing ones. Many patterns of human behaviors have consequences that lie in the far future: think for example of the process of aging wine or balsamic vinegar. A producer might put to rest a product that he or she may never get to taste in the future. Why and how can it happen? Although delaying reinforcement is a peculiar behavior that has brought many advantages to human beings, there are conditions in which it can be problematic.

It seems to be yet an open question whether reinforcement can be seen to select or construct complex forms of stimulus control (e.g., Sidman, 1994). For example, the three-term contingency analysis formulated by Skinner (1953) does not seem to be comprehensive enough to account for the transformation of stimulus function whenever there is no direct reinforcement available to maintain a responding. This may apply to hypothetical and delayed rewards, whose attainment is a function of choices that we take in the present and which comprises one of the most fertile avenues of inquiry within the field of BA and BE (i.e. delay discounting; e.g., Green \& Myerson, 2004; Rachlin, 1995). Delay discounting is a phenomenon widely addressed in both BA and $\mathrm{BE}$ and may be considered as a special type of bias. It refers to the subjective devaluation of outcomes or consequences as a function of time (but also probabilities, social proximity, etc.) and is usually depicted by the coefficient $k$. However, there are important differences when examining delay discounting according to either the BA or BE traditions.

From a behavioral standpoint, delay discounting can be described as a process in which reinforcers are devalued as time to receipt increases (Rachlin \& Green, 1972). That is, the value of a reinforcing consequence (e.g., money) tends to decrease as a function of the delay up to the point of delivery of the consequence. This phenomenon can help describe and explain a wide variety of dysfunctional behaviors. In many occasions, the immediate consequences of harmful behaviors such as smoking, taking drugs, or overeating are more concrete and are available in a shorter time after the behavior occurs. Hence, these consequences have a higher reinforcing value compared to alternative behaviors that would have better consequences but are either abstract or will occur in the future (or both).

For example, if we were asked to change current behaviors whose most detrimental consequences are likely to occur no sooner than in the distant and uncertain future (e.g., global warming), these be- 
havior changes seem unlikely to occur. In fact, the long delay between a person's unsustainable behavior and any direct negative critical consequences may have little effect on behavior when more immediate consequences control incompatible behavior (Reed et al., 2013). However, differences in the delay discounting curves have been found among species (e.g. Green, 2010; Green, Myerson, Holt, Slevin, \& Estle, 2004) as well as among individuals (e.g. Dixon, Marley, \& Jacobs, 2003).

Self-control is strictly related to delay discounting, insofar as it comprises a form of subjectively devaluing one's own future consequences of choice. More formally put, self-control refers to the ability to choose a larger reinforcer that is delayed in time over smaller but immediate one (Grosch \& Neuringer, 1981; Logue, Pena-Correal, Rodriguez, \& Kabela, 1986). Several studies have shown that this skill can vary among individuals. For example, people diagnosed with conduct, disruptive, or impulse control disorders choose more often immediate and smaller reinforcers than they choose large ones compared to individuals who do not have a similar diagnosis (Neef, Bicard, \& Endo, 2001; Neef, Bicard, Endo, Coury, \& Aman, 2005; Schweitzer \& Sulzer-Azaroff, 1988).

As McKeel and Dixon (2014) remarked, while several studies have shown the utilization of a standard self-control training procedure and variations of it by directly training people to opt for a delayed choice, there is evidence about the role of verbal mediation in teaching individuals to choose larger and more delayed reinforcers over smaller and immediate ones (e.g., Binder, Dixon, \& Ghezzi, 2000; Dixon \& Holton, 2009). We submit that an RFT perspective could be useful to explain how language may play an important role for manipulating responses in tasks that involve choices with delayed outcomes. According to Hayes et al. (2001), we can develop relations not only by making experiences with contingencies of reinforcement, but also by relating functions of stimuli that transfer from one to another. This complex set of learning skills can be explained through the ability of individuals to construct verbal language. In other words, verbal events play a major role in a large variety of behaviors, including choice and decision-making.
There is evidence of the relation between the steepness of delay discounting curves and high degrees of cognitive fusion, experiential avoidance, and difficulties in engaging in valued action (Levin, Haeger, Ong, \& Twohig, 2018). In other words, individuals who show a steeper discounting curve have a greater tendency to enact avoidant and fused actions that allow them to have immediate access to short-term reinforcement, despite long-term costs for valued action (Levin et al., 2018). Adopting an RFT-based training allows to alter the relation between verbal stimuli. Applying RFT-derived interventions to people who display low levels of self-control may be effective for flattening their otherwise steep discounting curve. This is what has been shown by applying ACT-based trainings aimed to enhance individual psychological flexibility (e.g., Hendrickson \& Rasmussen, 2013; Morrison, Madden, Odum, Friedel, \& Twohig, 2014).

An augmental, differently to pliance and tracking, does not specify consequences or contingencies but changes the reinforcing value of the consequences specified in the rule (Torneke, Luciano \& Salas, 2008). Augmental rules are of particular interest in this context, for they are at the basis of values in ACT terminology: that is, "freely chosen, verbally constructed consequences of ongoing, dynamic, evolving patterns of activity, which establish predominant reinforcers for that activity that are intrinsic in engagement in the valued behavioral pattern itself” (Wilson \& DuFrene 2009, p. 66). Augmental rules share some features with the concept of $\mathrm{MO}$, inasmuch as it depicts an event that can temporary "alter the effectiveness of reinforcers or punishers (the value-altering effect) and the frequency of operant response classes related to those consequences (the behavior altering effect)" (Laraway, Snycerski, Michael, \& Poling, 2003, p. 412). Similar to MOs, augmenting rules have the property to alter the reinforcing value of other stimuli. However, the latter derive their functional properties through language while the former derive them through a specific history of learning with the environment (Hoffmann, Contreras, Clay, \& Twohig, 2016). 


\section{Reorienting the Agent Towards a System of (Value) Change}

Health and prevention behavior comprise two fields in which delayed reinforcement is at stake: changes in lifestyle (e.g. dieting, increased motor activity and smoking cessation) can add up to prevent life-threatening diseases and events in the future. Utility and effectiveness of interventions on health behavior changes are judged by the promotions of sustained and desired behavior in the long term. Most studies on changing health behavior have focused on investigating the cognitive and emotional variables that are thought to support long-term behavior change (Schwarzer, 2008). Notwithstanding, these approaches have only partially explained the maintenance of the change in health behavior (Kwasnicka, Dombrowski, White, \& Sniehotta, 2016). A possible initiative can be offered by a context-driven approach. Health behavior change is a dynamic process and a context-driven approach that can be useful to understand and predict health behavior change (Hayes, 2004).

RFT offers a detailed analysis of the influence of language on complex human behavior by analyzing changes in health behavior and allowing to analyze how specific verbal rules exercise control over response (Barnes \& Keenan, 1993; Carpentier, Smeets, \& Barnes-Holmes, 2002). Behavior change should not only act on the interruption of unhealthy behaviors, but also on strengthening or weakening existing relational responses and learning new relational responses in the context of healthy behaviors. Studies on relational frames and derived relational responding allow us to analyze how any healthy or unhealthy behavior depends not only on its direct consequences, but also on the relational network that encompass the response; in fact, it is also under symbolic contextual control (Barnes-Holmes \& BarnesHolmes, 2000; Hayes, 1994; Hayes et al., 2001).

Since symbolic behavior cannot be erased or unlearned, and mutual and combinatorial entailment bear generative properties, behavior change is made more difficult because each stimulus is part of a relational network and rules contain stimuli that are part of those networks. Consequently, as we evoke a rule to try to control our behavior (e.g., "I'm dieting and I must not eat chocolate cake"), at the same time we bear into the present unhealthy stimulus functions that make violating the rule more probable, evoking exactly the unhealthy behavior that we are trying to control (Wegner, 1994). For example, the word chocolate might evoke flavors, smells, salivation or emotions. Conversely, the words dieting and must evoke feelings of constrictions and life-long sufferance; they can evoke behavior aimed to control them while hindering to eat the chocolate cake. Conceptualizing symbolic behavior as a particular relational repertoire sheds light on why our habits are so resistant to change and enriches our level of understanding of why we opt away from unhealthy behavior, even when we are very motivated and we are aware of the rules that lead to healthy behavior. In sum, there are imbricated components that rest on the individual's learning history and others that rest on the functional properties of symbolic relational behavior.

To overcome the paradox of evoking dysfunctional behavior by trying to control it with verbal antecedents and interpreting adherence to the rule as a success and non-adherence as a failure, behavior change can occur and be maintained if the rule does not take the form of a goal to achieve success; conversely, the rule should assume a domain of value (Butryn, Forman, Hoffman, Shaw, \& Juarascio, 2011; Lillis, Hayes, Bunting, \& Masuda, 2009). A previously noted, ACT (Hayes, Strosahl, \& Wilson, 1999) stemmed from RFT as an approach to behavior change. ACT researchers and therapists strive to increase psychological flexibility to help individuals live a rich and meaningful life. According to Kashdan and Rottenberg (2010), there are four aspects of psychological flexibility that promote health behavior change in a real-life context: (i) recognizing and adapting to different situational demands; (ii) shifting perspective when personal or social functioning are not useful; (iii) finding balance of competing desires, needs, and life domains; and (iv) being aware and committed to behaviors that are congruent with deeply held values. Several studies have demonstrated the effectiveness of ACT interventions for the promotion of healthy behaviors, such as physical activity (e.g., Butryn et al., 2011; Moffitt \& Mohr, 2015), smoking cessation (e.g., Bricker et al., 2014, 2017; Gifford et al., 2004, 2011; Hernández-López, Luciano, Bricker, Roales- 
Nieto, \& Montesinos, 2009), weight management (e.g., Forman \& Butryn, 2015; Lillis et al., 2009; Lillis \& Kendra, 2014).

\section{Counterproductive Strategies: Values and Decision-Making}

Framing influences decision-making: this is one of the conceptual tenets of prospect theory (Kahneman \& Tversky, 1979), whose robustness rests on several empirical observations (see Barberis, 2013). Relating information and facts in terms of losses or gains can influence valuing patterns of actions. For example, the lockdowns enacted by several governments in response to the novel coronavirus pandemic was commonly referred as an avoidance of life losses in the hope of saving as many lives as possible thanks to social containment measures. Herein, saving human lives may be an archetypical example, for it would feed some ethical concerns if compared to a system of values ranked similarly to economic losses (e.g., due to the disruption of air traffic, or the cancellation of exhibitions, concerts, or sports events).

Choice and decision-making processes may be characterized by value propositions: specifically, whenever the effects of that choice or decision may not be experienced contingently, rules and relations may help bridge present behavior with non-contingent consequences. Furthermore, value propositions may affect consumer behavior (i.e., by stating the promised benefits and gains vs. costs that a consumer will experience following the purchase of a certain good). Some of the most complex and difficult phenomena that affect our societies and environment (e.g., overpopulation, pollution, war, famine, and other wicked problems) possess this feature and rely on the impossibility of experiencing direct contingencies of reinforcement; thus, they require verbal mediation (see Coyne, 2005). They represent examples of a class of consequences of irrationality comprising counterproductive strategies. Although the present work is concerned with a more recent approach to human language and values, "One reason people might prize socially constructed reinforcement over intrinsic reinforcement is sociocultural programming" (Dahl, Steward, Martell, \& Kaplan, 2013, p. nd), which draws heavily on the importance of language, mediation and transfer of skills and knowledge of the sociocultural theory of Vygotsky (1978). Within the $\mathrm{BE}$ tradition values refer to a collection of attitudes that an agent may have toward general and abstract phenomena (e.g., pollution, peace, etc.) and reach beyond the level of the individual or group; in the latter case, it is more appropriate to refer to them as attitudes, which represent evaluative tendencies (e.g., towards one's family member, colleague, etc.; Warr, 2002; see also Stewart, Barnes-Holmes, Barnes-Holmes, Bond, \& Hayes, 2006). The BE tradition takes into account the role of values primarily inasmuch as the calculation and computation of functions are concerned: that is, value functions are curves for displaying the gains or losses of an agent relative to a psychologically neutral reference point (van der Pligt, 2001). Whereas for RFT they are verbally constructed contingencies, which affect the agent's behavior insofar as he or she considers them hierarchically in symbolic relation to ongoing patterns of behavior and take the form of as "chosen qualities of action patterns [...] that people can work toward, but that they cannot arrive at once-and-for-all" (Bond, Hayes, \& Barnes-Holmes, 2006, pp. 33-34).

\section{Values as a Compass in Decision Making}

As humans, we are able to transfer the properties of some objects to new and different stimuli thanks to temporal, space, coordination, comparative, or causal framing, and so on. For example, we can establish causal links between temporally or spatially separated events. Moreover, we can compare different situations with the intention of finding similarities or differences. Likewise, the symbolic properties of verbal language allow us to make the past figuratively relevant, not only in cognitive and imaginative terms, but also inasmuch as emotional and physiological activations are concerned. Thanks to the symbolic repertoire that we commonly call language, we can devise plans and forecasts for the future. The possibility of verbally (symbolically) representing desires and directions that can give a sense of fullness to life is a fundamental prerequisite to be able to choose, identify, and cultivate one's values, while learning to move in tune with them. They indicate directions of life and 
do not coincide with specific actions that have directly observable repercussions and consequences.

Values are our deepest desires about how we would like to be and how we would like to interact with others, the world, and ourselves. They comprise principles that guide and motivate us throughout our lives and allow us to give more fullness to our existence. The identification of a value is the result of the intimate, free, and personal choice of an individual who acts accordingly and feels that he or she gives greater authenticity, vitality, and fullness to his or her existence. Hayes (2005) defined values as directions of life, desired, global and verbally constructed choices. Directions of life refer to "qualities of actions", which by nature are neither static nor immutable over time. Values refer to the continuous and global qualities of actions: that is, they refer to a continuous action over time, where the focus is on the way one wants to behave and not on the goal one wants to achieve.

The identification of values favors the processes of acceptance, availability, and openness to the individual experience (even if it is painful), giving dignity to his or her efforts. Moreover, values represent a fundamental motivational aspect, helping the agent to engage in concrete actions that follow the direction indicated by the values he or she has chosen. Values can be conceptualized as the result of choices. Identifying and pursuing a value means choosing between different alternatives, preferring the option that contributes the most to making one's life full and rich. The direction indicated by the values allow the individual to orient individuals along the entire path of their existence, motivating them to remain focused even when life puts him or her to the test.

In some circumstances, it may be difficult to shift to long-term control, especially when shortterm reinforcers are stronger and long-term ones are less tangible. For example, recycling behavior is mostly a value-based action that allows the agent to overcome the effects described by the curve that characterizes a preference for plastic shopping bags to plastic-free, albeit more expensive shopping bags. Since buying plastic shopping bags might generate economic savings that can be used for buying other goods, addressing the agent's behavior toward spending more for plastic-free shopping bags can only be achieved verbally. By symbolically representing and valuing the future consequences of the agent's actions and relating these to a specific purpose, a punishing contingency becomes a reinforcing one due to the transformation of stimulus function. In other words, assigning verbal value to the agent's action in the present and bridging the present consequences and desirable future ones, is the only way to counteract any discounting effects. The same applies even when some elements are unseen and unforeseen, such as the immediate reinforcing contingencies of going out to meet friends versus "avoiding an untouchable danger" during the Covid-19 lockdown. Similarly, the only way to counteract these contingencies is to assign value to the punishing consequences of staying at home in light of avoiding health problems to ourselves and our loved ones.

However, it may be the case that the symbolic function of values interferes with the identification of values themselves. This may lead to a difficulty to conceptually distinguishing between evaluations, judgments, and values. Furthermore, due to the symbolic function of language and reflecting what our culture predisposes, we can be very sensitive and result oriented. Thus, agents may iteratively monitor what they are doing, how successful they are compared to their past selves and others, fantasize about how and when they will achieve a better state of mind, or just feel the need to justify their own or others' behavior. In sum, choosing a direction of life and having values is self-reinforcing, although it does not require continuous monitoring.

\section{Conclusions: RFT Beyond Applicative Implications}

RFT offers a conceptualization of cognition in terms of a repertoire of relational responding, according to which biases are not intrinsically seen as limits of the system that may hinder our choices and decisions. Biases are rather a product of our processes of symbolic derivations that are contextually controlled and that occasion verbally controlled behavior. Human behavior is a function of the large physical and symbolic context in which it occurs, and verbal process can shape it continu- 
ously. Moreover, augmental rules can contribute towards changing the meaning of usually punishing contingencies, while helping individuals to cross the "mud" of psychological suffering.

RFT offers a timely and pragmatic dimension for understanding and modifying (dysfunctional) conduct. It expands the traditional behavior analytic root to contextual behavior and reaches out to the cognitive tradition of BE by offering alternative and meaningful analyses of cognitive phenomena in decision making. This way, the notion of utility as a truth criterion for context-based analyses is tracked in the strong interconnection and continuity between basic research and applied interventions, which is also the case in BA. Whereas behavior analytic models have been able to exhaustively describe and explain behavior change (including choice, biases and a systems of values), we call for contributions from RFT to integrate our descriptions and explanations of the cognitive side of behavior change. This, we submit, may expand BA with the conceptualization of phenomena that are electively domain of research in BE.

\section{Funding information}

This article received no external funding.

\section{Acknowledgements}

The authors are grateful to César Antonio Alves da Rocha and to an anonymous reviewer for their helpful comments and suggestions. Thanks to Francesco Ciaccia and Flora Moura Lorenzo for translating the abstract respectively into Spanish and Portuguese.

\section{Ethics Statement}

This article does not contain any studies with human participants or animals performed by any of the authors.

\section{Conflict of interest}

The authors have contributed to all the parts of the manuscript. The authors certify that they have no affiliations with or involvement in any organization or entity with any financial or non-financial in the subject matter or materials discussed in this manuscript.

\section{References}

Angner, E., \& Loewenstein, G. (2007). Behavioral economics. Handbook of the philosophy of science, 5, 641-690. Retrieved from https:// www.cmu.edu/dietrich/sds/docs/loewenstein/ BehavioralEconomics.pdf

Barberis, N. C. (2013). Thirty years of prospect theory in economics: A review and assessment. Journal of Economic Perspectives, 27(1), 173196. doi:10.1257/jep.27.1.173

Barbero-Rubio, A., López-López, J. C., Luciano, C., \& Eisenbeck, N. (2016). Perspective-taking measured by implicit relational assessment procedure (IRAP). The Psychological Record, 66, 243-252. doi:10.1007/s40732-016-0166-3

Barnes, D., \& Keenan, M. (1993). A transfer of functions through derived arbitrary and nonarbitrary stimulus relations. Journal of the Experimental Analysis of Behavior, 59, 61-81. doi:10.1901/jeab.1993.59-61

Barnes-Holmes, D., \& Barnes-Holmes, Y. (2000). Explaining complex behavior: Two perspectives on the concept of generalized operant classes. The Psychological Record, 50, 251-265. doi:10.1007/BF03395355

Barnes-Holmes, D., Barnes-Holmes, Y., Luciano, C., \& McEnteggart, C. (2017). From the IRAP and REC model to a multi-dimensional multilevel framework for analyzing the dynamics of arbitrarily applicable relational responding. Journal of Contextual Behavioral Science, 6(4), 434-445. doi:10.1016/j.jcbs.2017.08.001

Barnes-Holmes, D., Barnes-Holmes, Y., \& McEnteggart, C. (2020). Updating RFT (more field than frame) and its implications for process-based therapy. The Psychological Record, 70, 605-624. doi:10.1007/s40732-019-00372-3

Barnes-Holmes, D., Barnes-Holmes, Y., Power, P., Hayden, E., Milne, R., \& Stewart, I. (2006). Do you really know what you believe? Developing the implicit relational assessment procedure (IRAP) as a direct measure of implicit beliefs. The Irish Psychologist, 32(7), 169-177. Retrieved from https://www.researchgate.net/ profile/Ian_Stewart3/publication/241832168 
Barnes-Holmes, D., Barnes-Holmes, Y., Stewart, I., \& Boles, S. (2010). A sketch of the implicit relational assessment procedure (IRAP) and the relational elaboration and coherence (REC) model. The Psychological Record, 60, 527-542. doi:10.1007/BF03395726

Barnes-Holmes, Y., Barnes-Holmes, D., Roche, B., \& Smeets, P. M. (2001a). Exemplar training and a derived transformation of function in accordance with symmetry. The Psychological Record, 51, 287-308. doi:10.1007/BF03395400

Barnes-Holmes, Y., Barnes-Holmes, D., Roche, B., \& Smeets, P. M. (2001b). Exemplar training and a derived transformation of function in accordance with symmetry: II. The Psychological Record, 51, 589-603. Retrieved from http:// mural.maynoothuniversity.ie/10676/1/BRExemplar-II-2001.pdf

Barnes-Holmes, D., Murphy, A., Barnes-Holmes, Y., \& Stewart, I. (2010). The implicit relational assessment procedure: Exploring the impact of private versus public contexts and the response latency criterion on pro-white and anti-black stereotyping among white Irish individuals. The Psychological Record, 60, 57-79. doi:10.1007/BF03395694

Baumeister, R. F. (2001). The psychology of irrationality: Why people make foolish, selfdefeating choices. In I. Brocas \& J. D. Carillo (Eds.), The psychology of economic decisions (pp. 3-16). Oxford, United Kingdom: Oxford University Press.

Bickel, W., Jarmolowicz, D., Mueller, E., \& Gatchalian, K. (2011). The behavioral economics and neuroeconomics of reinforcer pathologies: Implications for etiology and treatment of addiction. Current Psychiatry Reports, 13(5), 406-415. doi:10.1007/s11920-011-0215-1

Binder, L. M., Dixon, M. R., \& Ghezzi, P. M. (2000). A procedure to teach self-control to children with attention deficit hyperactivity disorder. Journal of Applied Behavior Analysis, 33(2), 233-237. doi:10.1901/jaba.2000.33-233

Bond, F. W., Hayes, S. C., \& Barnes-Holmes, D. (2006). Psychological flexibility, ACT, and organizational behavior. Journal of Organizational Behavior Management, 26(1-2), 25-54. doi:10.1300/J075v26n01_02
Bordieri, M. J., Kellum, K. K., Wilson, K. G., \& Whiteman, K. C. (2016). Basic properties of coherence: Testing a core assumption of relational frame theory. The Psychological Record, 66(1), 83-98. doi:10.1007/s40732-015-0154-z

Brandon, P. (2008). BEHAVIORAL behavioral economics [Review of the book Nudge: Improving decisions about health, wealth, and happiness, by R. H. Thaler \& C. R. Sunstein]. Retrieved from https://www.amazon.com/review/ R3FC6CUFXEZTWC.

Bricker, J. B., Copeland, W., Mull, K. E., Zeng, E. Y., Watson, N. L., Akioka, K. J., \& Heffner, J. L. (2017). Single-arm trial of the second version of an acceptance \& commitment therapy smartphone application for smoking cessation. Drug and Alcohol Dependence, 170, 37-42. doi:10.1016/j.drugalcdep.2016.10.029

Bricker, J. B., Mull, K. E., Kientz, J. A., Vilardaga, R., Mercer, L. D., Akioka, K. J., \& Heffner, J. L. (2014). Randomized, controlled pilot trial of a smartphone app for smoking cessation using acceptance and commitment therapy. Drug and Alcohol Dependence, 143, 87-94. doi:10.1016/j. drugalcdep.2014.07.006

Butryn, M. L., Forman, E., Hoffman, K., Shaw, J., \& Juarascio, A. (2011). A pilot study of acceptance and commitment therapy for promotion of physical activity. Journal of Physical Activity and Health, 8, 516-522. doi:10.1123/jpah.8.4.516

Camerer, C. (1999). Behavioral economics: Reunifying psychology and economics. Proceedings of the National Academy of Sciences, 96(19), 10575-10577. doi:10.1073/ pnas.96.19.10575

Camerer, C., Loewenstein, G. and Rabin, M. (2004). Advances in behavioral economics. Princeton, NJ: Princeton University Press.

Campbell, C., Barnes-Holmes, Y., Barnes-Holmes, D., \& Stewart, I. (2011). Exploring screen presentations in the implicit relational assessment procedure (IRAP). International Journal of Psychology and Psychological Therapy, 11, 377388. Retrieved from http://mural.maynoothuniversity.ie/4958/1/YBH_exploring.pdf Carpentier, F., Smeets, P. M., \& Barnes-Holmes, D. (2002). Establishing transfer of compound control in children: A stimulus control analy- 
sis. The Psychological Record, 52, 139-158. doi:10.1007/BF03395420

Carr, J. E., Luke, M. M., \& Arntzen, E. (2019). On recent attempts to rebrand "behavior analysis" as "behavior science". European Journal of Behavior Analysis, 21(1) 20-25. doi:10.1080/15 021149.2019 .1611130

Catania, A. C. (1995). Higher-order behavior classes: Contingencies, beliefs, and verbal behavior. Journal of Behavior Therapy and Experimental Psychiatry, 26(3), 191-200. doi:10.1016/00057916(95)00033-V

Catania, A. C., Shimoff, E., \& Matthews, B. A. (1987). Correspondence between definitions and procedures: A reply to Stokes, Osnes, and Guevremont. Journal of Applied Behavior Analysis, 20(4), 401-404. doi:10.1901/ jaba.1987.20-401

Cesareo, M. (2018). Behavioral economics and behavioral change policies: Theoretical foundations and practical applications to promote well-being in the Italian context. (Doctoral dissertation). International University of Language and Media (IULM), Milano, Italy. Retrieved from http://hdl.handle.net/10808/26204

Coyne, R. (2005). Wicked problems revisited. Design Studies, 26(1), 5-17. doi:10.1016/j. destud.2004.06.005

Dahl, J., Steward, I., Martell, C., \& Kaplan, J. S. (2013). ACT and RFT in relationships: Helping clients deepen intimacy and maintain healthy commitments using acceptance and commitment therapy and relational frame theory. Reno, NV: Context Press/New Harbinger.

De Houwer, J., Heider, N., Spruyt, A., Roets, A., \& Hughes, S. (2015). The relational responding task: Toward a new implicit measure of beliefs. Frontiers in Psychology, 6, 319. doi:10.3389/fpsyg.2015.00319

De Houwer, J., \& Hughes, S. (2019). Toward a cumulative science of emotion: A functional-cognitive framework for emotion research. Cognition \& Emotion, 33, 61-66. doi:10.1080/02699931.2 018.1504750

De Houwer, J., Hughes, S., \& Barnes-Holmes, D. (2017a). Bridging the divide between functional and cognitive psychology. Journal of Applied Research in Memory and Cognition, 6(1), 47-50. doi:10.1016/j.jarmac.2017.01.001

De Houwer, J., Hughes, S., \& Barnes-Holmes, D. (2017b). Psychological engineering: A functional-cognitive perspective on applied psychology. Journal of Applied Research in Memory and Cognition, 6(1), 1-13. doi:10.1016/j.jarmac.2016.09.001

De Houwer, J., \& Hughes, S. (2020). The Psychology of learning: A functional-cognitive perspective. Cambridge, MA: The MIT Press.

Dixon, M. R., Hayes, L. J., \& Aban, I. B. (2000). Examining the roles of rule following, reinforcement, and preexperimental histories on risk-taking behavior. The Psychological Record, 50(4), 687-704. doi:10.1007/BF03395378

Dixon, M. R., \& Holton, B. (2009). Altering the magnitude of delay discounting by pathological gamblers. Journal of Applied Behavior Analysis, 42(2), 269-275. doi:10.1901/jaba.2009.42-269

Dixon, M. R., Marley, J., \& Jacobs, E. A. (2003). Delay discounting by pathological gamblers. Journal of Applied Behavior Analysis, 36(4), 449-458.

doi:10.1901/jaba.2003.36-449

Dymond, S., May, R. J., Munnelly, A., \& Hoon, A. E. (2010). Evaluating the evidence base for relational frame theory: A citation analysis. The Behavior Analyst, 33(1), 97-117. doi:10.1007/ BF03392206

Forman, E. M., and Butryn, M. L. (2015). A new look at the science of weight control: How acceptance and commitment strategies can address the challenge of self-regulation. Appetite, 84, 171-180. doi:10.1016/j.appet.2014.10.004

Gifford, E. V., Kohlenberg, B. S., Hayes, S. C., Antonuccio, D. O., Piasecki, M. M., RasmussenHall, M. L., \& Palm, K. M. (2004). Acceptancebased treatment for smoking cessation. Behavior Therapy, 35, 689-705. doi:10.1016/ S0005-7894(04)80015-7

Gifford, E. V., Kohlenberg, B. S., Hayes, S. C., Pierson, H. M., Piasecki, M. P., Antonuccio, D. O., \& Palm, K. M. (2011). Does acceptance and relationship focused behavior therapy contribute to bupropion outcomes? A randomized controlled trial of functional analytic psychotherapy and acceptance and commitment therapy for smoking cessation. Behavior Therapy, 
42, 700-715. doi:10.1016/j.beth.2011.03.002

Gigerenzer, G., Hertwig, R. \& Pachur, T. (2011). Heuristics. Oxford, United Kingdom: Oxford University Press.

Gigerenzer, G., Todd, P. M., \& ABC Research Group (1999). Simple heuristics that make us smart. New York, NY: Oxford University Press.

Goldstein, D. G., \& Gigerenzer, G. (2002). Models of ecological rationality: The recognition heuristic. The Psychological Review, 109(1), 75-90. doi:10.1037/0033-295X.109.1.75

Gomes, C., Perez, W., de Almeida, J., Ribeiro, A., de Rose, J., \& Barnes-Holmes, D. (2020). Assessing a derived transformation of functions using the implicit relational assessment procedure under three motivative conditions. The Psychological Record, 69, 487-497. Retrieved from https://gorft.com/wp-content/uploads/2019/10/IRAPpepper.pdf

Green, L. (2010). Delay discounting by humans and other animals: Does the species matter? Neurotoxicology and Teratology, 4(32), 496-496. doi:10.1016/j.ntt.2010.04.002

Green, L., \& Myerson, J. (2004). A discounting framework for choice with delayed and probabilistic rewards. Psychological Bulletin, 130(5), 769-792. doi:10.1037/0033-2909.130.5.769

Green, L., Myerson, J., Holt, D. D., Slevin, J. R., \& Estle, S. J. (2004). Discounting of delayed food rewards in pigeons and rats: Is there a magnitude effect?. Journal of the Experimental Analysis of Behavior, 81(1), 39-50. doi:10.1901/ jeab.2004.81-39

Grosch, J., \& Neuringer, A. (1981). Self-control in pigeons under the Mischel paradigm. Journal of the Experimental Analysis of Behavior, 35(1), 3-21. doi:10.1901/jeab.1981.35-3

Hayes, S. C. (1994). Relational frame theory: A functional approach to verbal events. In S. C. Hayes, L. J. Hayes, O. Sato, \& K. Ono (Eds.), Behavior analysis of language and cognition (pp. 9-30). Reno, NV: Context Press.

Hayes, S. C. (2004). Acceptance and commitment therapy, relational frame theory, and the third wave of behavioral and cognitive therapies. Behavior Therapy, 35, 639-665. doi:10.1016/ S0005-7894(04)80013-3
Hayes, S. C. (2005). Get out of your mind and into your life: The new acceptance and commitment therapy. Oakland, CA: New Harbinger.

Hayes, S. C., \& Brownstein, A. J. (1986). Mentalism, behavior-behavior relations, and a behavioranalytic view of the purposes of science. The Behavior Analyst, 9(2), 175-190. doi:10.1007/ bf03391944

Hayes, S. C., \& Brownstein, A. J. (1985). Verbal behavior, equivalence classes, and rules: New definitions, data, and directions. Annual meeting of the Association for Behavior Analysis, Columbus, $\mathrm{OH}$.

Hayes, S. C., Barnes-Holmes, D., \& Roche, B. (Eds.). (2001). Relational Frame Theory: A PostSkinnerian account of human language and cognition. New York, NY: Plenum Press.

Hayes, S. C., Bond, F. W., Barnes-Holmes, D., \& Austin, J. (2006). Acceptance and mindfulness at work: Applying acceptance and commitment therapy and relational frame theory to organizational behavior management. New York, NY: Routledge.

Hayes, S. C., Strosahl, K. D., \& Wilson, K. G. (1999). Acceptance and commitment therapy: An experiential approach to behavior change. New York, NY: Guilford Press.

Hayes, S. C., Strosahl, K. D., \& Wilson, K. G. (2012). Acceptance and commitment therapy: An experiential approach to behavior change 2 nd edition. New York, NY: Guilford Press.

Hayes, S. C., Zettle, \& Rosenfarb, I. (2004). Rulefollowing. In Hayes, S.C. (Ed.), Rule-governed behavior: Cognition, contingencies, and instructional control (pp. 191-218). Reno, NV: Context Press.

Heinicke, M. R., Carr, J. E., Leblanc, L. A., \& Severtson, J. M. (2010). On the use of fluency training in the behavioral treatment of autism: a commentary. The Behavior Analyst, 33(2), 223229. doi:10.1007/BF03392221

Hendrickson, K. L., \& Rasmussen, E. B. (2013). Effects of mindful eating training on delay and probability discounting for food and money in obese and healthy-weight individuals. Behaviour Research and Therapy, 51(7), 399409. doi:10.1016/j.brat.2013.04.002 
Hernández-López, M., Luciano, M. C., Bricker, J. B., Roales-Nieto, J. G., \& Montesinos, F. (2009). Acceptance and commitment therapy for smoking cessation: A preliminary study of its effectiveness in comparison with cognitive behavioral therapy. Psychology of Addictive Behaviors, 23, 723-730. doi:10.1037/a0017632

Hoffmann, A. N., Contreras, B. P., Clay, C. J., \& Twohig, M. P. (2016). Acceptance and commitment therapy for individuals with disabilities: A behavior analytic strategy for addressing private events in challenging behavior. Behavior Analysis in Practice, 9(1), 14-24. doi:10.1007/ s40617-016-0105-4

Howell, A. J., \& Passmore, H. A. (2019). Acceptance and commitment training (ACT) as a positive psychological intervention: A systematic review and initial meta-analysis regarding act's role in well-being promotion among university students. Journal of Happiness Studies, 20, 1995 2010. doi:10.1007/s10902-018-0027-7

Hughes, S. J., \& Barnes-Holmes, D. (2013). A functional approach to the study of implicit cognition: The IRAP and the REC model. In S. Dymond, \& B. Roche (Eds.), Advances in relational frame theory: Research \& applications (pp. 97-126). Oakland, CA: New Harbinger.

Hughes, S., Barnes-Holmes, D., \& Vahey, N. (2012). Holding on to our functional roots when exploring new intellectual islands: A voyage through implicit cognition research. Journal of Contextual Behavioral Science, 1(1-2), 17-38. https://doi.org/10.1016/j.jcbs.2012.09.003

Hursh, S. (1980). Economic concepts for the analysis of behavior. Journal of the Experimental Analysis of Behavior, 34(2), 219-238. doi:10.1901/jeab.1980.34-219

Jensen, R., \& Burgess, H. (1997). Mythmaking: How introductory psychology texts present BF Skinner's analysis of cognition. The Psychological Record, 47(2), 221-232. doi:10.1007/BF03395221

Jones, B., \& Rachlin, H. (2006). Social discounting. Psychological Science, 17(4), 283-286. doi:10.1111/j.1467-9280.2006.01699.x

Kahneman, D. (2003a). A perspective on judgment and choice: Mapping bounded rationality. American Psychologist, 58(9), 697-720.
doi:10.1037/0003-066X.58.9.697

Kahneman, D. (2003b). Maps of bounded rationality: Psychology for behavioral economics. The American Economic Review, 93(5), 14491475. Retrieved from https://www.jstor.org/ stable/3132137

Kahneman, D. (2011). Thinking, fast and slow. New York, NY: Farrar, Straus and Giroux.

Kahneman, D., Slovic, P., \& Tversky, A. (1982). Judgment under uncertainty: Heuristics and biases. Cambridge, United Kingdom: Cambridge University Press.

Kahneman, D., \& Tversky, A. (1979). Prospect theory: An analysis of decision under risk. Econometrica, 47(2), 263-291. doi:10.2307/1914185

Kashdan, T. B., \& Rottenberg, J. (2010). Psychological flexibility as a fundamental aspect of health. Clinical Psychology Review, 30, 865-878. doi:10.1016/j.cpr.2010.03.001

Kwasnicka, D., Dombrowski, S. U., White, M., \& Sniehotta, F. (2016). Theoretical explanations for maintenance of behaviour change: A systematic review of behaviour theories. Health Psychology Review, 10, 277-296. doi:10.1080/1 7437199.2016 .1151372

Langthorne, P., \& McGill, P. (2009). A tutorial on the concept of the motivating operation and its importance to application. Behavior Analysis in Practice, 2(2), 22-31. doi:10.1007/bf03391745

Laraway, S., Snycerski, S., Michael, J., \& Poling, A. (2003). Motivating operations and terms to describe them: Some further refinements. Journal of Applied Behavior Analysis, 36(3), 407-414. doi:10.1901/jaba.2003.36-407

Levin, M. E., Haeger, J., Ong, C. W., \& Twohig, M. P. (2018). An examination of the transdiagnostic role of delay discounting in psychological inflexibility and mental health problems. The Psychological Record, 68(2), 201-210. doi:10.1007/s40732-018-0281-4

Lillis, J., \& Kendra, K. E. (2014). Acceptance and commitment therapy for weight control: Model, evidence, and future directions. Journal of Contextual Behavioral Science, 3, 1-7. doi:10.1016/j.jcbs.2013.11.005

Lillis, J., Hayes, S. C., Bunting, K., \& Masuda, A. (2009). Teaching acceptance and mindfulness to improve the lives of the obese: A pre- 
liminary test of a theoretical model. Annals of Behavioral Medicine, 37, 58-69. doi:10.1007/ s12160-009-9083-x

Logue, A. W., Peña-Correal, T. E., Rodriguez, M. L., \& Kabela, E. (1986). Self-control in adult humans: Variation in positive reinforcer amount and delay. Journal of the Experimental Analysis of Behavior, 46(2), 159-173. doi:10.1901/ jeab.1986.46-159

McKeel, A. N., \& Dixon, M. R. (2014). Furthering a behavior analytic account of self-control using relational frame theory. Behavioral Development Bulletin, 19(2), 111. doi:10.1037/h0100581

Moffitt, R., \& Mohr, P. (2015). The efficacy of a selfmanaged acceptance and commitment therapy intervention DVD for physical activity initiation. British Journal of Health Psychology, 20, 115-129. doi:10.1111/bjhp.12098

Morrison, K. L., Madden, G. J., Odum, A. L., Friedel, J. E., \& Twohig, M. P. (2014). Altering impulsive decision making with an acceptancebased procedure. Behavior Therapy, 45(5), 630639. doi:10.1016/j.beth.2014.01.001

Neef, N. A., Bicard, D. F., \& Endo, S. (2001). Assessment of impulsivity and the development of self-control in students with attention deficit hyperactivity disorder. Journal of Applied Behavior Analysis, 34(4), 397-408. doi:10.1901/ jaba.2001.34-397

Neef, N. A., Bicard, D. F., Endo, S., Coury, D. L., \& Aman, M. G. (2005). Evaluation of pharmacological treatment of impulsivity in children with attention deficit hyperactivity disorder. Journal of Applied Behavior Analysis, 38(2), 135-146. doi:10.1901/jaba.2005.116-02

O'Connor, M., Farrell, L., Munnelly, A., \& McHugh, L. (2017). Citation analysis of relational frame theory: 2009-2016. Journal of Contextual Behavioral Science, 6(2), 152-158. doi:10.1016/j. jcbs.2017.04.009

O'Toole, C., \& Barnes-Holmes, D. (2009). Three chronometric indices of relational responding as predictors of performance on a brief intelligence test: The importance of relational flexibility. The Psychological Record, 59, 119-132. doi:10.1007/BF03395652
Palmer, D. C. (2004). Data in search of a principle: A review of relational frame theory: A postSkinnerian account of human language and cognition. Journal of the Experimental Analysis of Behavior, 81(2), 189-204. doi:10.1901/ jeab.2004.81-189

Puligandla, R. (1974). Fact and fiction in B. F. Skinner's science and utopia. An essay on philosophy of psychology. St. Louis, MO: Warren H. Green.

Quiñones, R., Hayes, L., \& Hayes, S. (2000). On the benefits of collaboration: Consumer psychology, behavioral economics and relational frame theory. Managerial and Decision Economics, 21(3/4), 159-165. Retrieved from http://www.jstor.org/stable/3108173

Rachlin, H. (1995). Behavioral economics without anomalies. Journal of the Experimental Analysis of Behavior, 64(3), 397-404. doi:10.1901/ jeab.1995.64-397

Rachlin, H., \& Green, L. (1972). Commitment, choice and self-control 1. Journal of the Experimental Analysis of Behavior, 17(1), 15-22. doi:10.1901/jeab.1972.17-15

Reed, D. D., Niileksela, C. R., \& Kaplan, B. A. (2013). Behavioral economics: A tutorial for behavior analysts in practice. Behavior Analysis in Practice, 6(1), 34-54. doi:10.1007/BF03391790

Schwarzer, R. (2008). Modeling health behavior change: How to predict and modify the adoption and maintenance of health behaviors. Journal of Applied Psychology, 57, 1-29. doi:10.1111/j.1464-0597.2007.00325.x

Schweitzer, J. B., \& Sulzer-Azaroff, B. (1988). Selfcontrol: Teaching tolerance for delay in impulsive children. Journal of the Experimental Analysis of Behavior, 50(2), 173-186. doi:10.1901/jeab.1988.50-173

Sidman, M. (1994). Equivalence relations: A research story. Boston, MA: Authors Cooperative.

Sidman, M., \& Tailby, W. (1982). Conditional discrimination vs. matching to sample: An expansion of the testing paradigm. Journal of the Experimental Analysis of Behavior, 37(1), 5-22. doi:10.1901/jeab.1982.37-5

Simon, H. A. (1955). A behavioral model of rational choice. Quarterly Journal of Economics, 69, 99-118. doi:10.2307/1884852 
Simon, H. A. (1972). Theories of bounded rationality. In C. B. McGuire \& R. Radner (Eds.), Decision and organization (pp. 161-176). Amsterdam, Netherlands: North-Holland Publishing Company.

Simon, H. A. (1983). Reason in human affairs. Stanford, CA: Stanford University Press.

Skinner, B. F. (1953). Science and human behavior. New York, NY: Free Press.

Skinner, B. F. (1966). An operant analysis of problem solving. In B. Kleinmuntz (Ed.), Problem solving: Research, method and theory. Hoboken, NJ: Wiley.

Skinner, B. F. (1974). About behaviorism. New York, NY: Knopf.

Smets, K. (2018, July 24). There is more to behavioral economics than biases and fallacies. Behavioral Scientist. Retrieved from https://behavioralscientist.org/there-is-more-to-behavioral-sciencethan-biases-and-fallacies/

Stanovich, K. E., \& West, R. F. (2000). Individual differences in reasoning: Implications for the rationality debate? Behavioral and Brain Sciences, 23(5), 645-665. doi:10.1017/ S0140525X00003435

Stewart, I., Barnes-Holmes, D., Barnes-Holmes, Y., Bond, F. W., \& Hayes, S. C. (2006). Relational frame theory and industrial/organizational psychology. In S. C. Hayes, F. W. Bond, D. BarnesHolmes, \& J. Austin (Eds.), Acceptance and mindfulness at work: Applying acceptance and commitment therapy and relational frame theory to organizational behavior management (pp. 55-90). Binghamton, NY: The Haworth Press.

Tagliabue, M., Squatrito, V., \& Presti, G. (2019). Models of cognition and their applications in behavioral economics: A conceptual framework for nudging derived from behavior analysis and relational frame theory. Frontiers in Psychology, 10, 2418. doi:10.3389/fpsyg.2019.02418

Thaler, R.H. (2016). Q\&A with Richard Thaler. In A. Samson (Ed.), The Behavioral economics guide 2016 (pp. 23-24). Retrieved from http://eprints. lse.ac.uk/66934/7/Samson_Behavioural\%20 economics\%20guide_\%202016_author.pdf

Todd, J. T., \& Morris, E. K. (1983). Misconception and miseducation: Presentations of radical behaviorism in psychology textbooks. The Behavior Analyst, 6(2), 153-160. doi:10.1007/ BF03392394

Tversky, A., \& Kahneman, D. (1974). Judgment under uncertainty: Heuristics and biases. Science, 185(4157), 1124-1131. doi:10.1126/science.185.4157.1124

Tversky, A., \& Kahneman, D. (1981). The framing of decisions and the psychology of choice. Science, 211(4481), 453-458. doi:10.1126/ science. 7455683

Vahey, N., Boles, S., \& Barnes-Holmes, D. (2010). Measuring adolescents' smoking-related social identity preferences with the implicit relational assessment procedure (IRAP) for the first time: A starting point that explains later IRAP evolutions. International Journal of Psychology and Psychological Therapy, 10(3), 453-474. Retrieved from https://www.redalyc. org/pdf/560/56017068008.pdf

van der Pligt, J. (2001). Psychology of decision making. In N. J. Smelser \& P. B. Baltes (Eds.), The international encyclopedia of the social and behavioral sciences, 5 (pp. 3309-3315). Oxford, England: Elsevier.

Vygotsky, L. S. (1978). Mind in society. Cambridge, MA: Harvard University Press.

Warr, P. (Ed) (2002). Psychology at work. London, United Kingdom: Penguin.

Wegner, D. M. (1994). Ironic processes of mental control. Psychological Review, 101, 34-52. doi:10.1037/0033-295X.101.1.34

Weinstein, J. H., Wilson, K. G., Drake, C. E., \& Kellum, K. K. (2008). A relational frame theory contribution to social categorization. Behavior and Social Issues, 17(1), 40-65. doi:10.5210/bsi. v17i1.406

Whelan, R., Barnes-Holmes, D., \& Dymond, S. (2006). The transformation of consequential functions in accordance with the relational frames of more-than and less-than. Journal of the Experimental Analysis of Behavior, 86(3), 317-335. doi:10.1901/jeab.2006.113-04

Wilkinson, N. (2008). An introduction to behavioral economics (1 ed.). London, United Kingdom: Palgrave Macmillan. 
Wilson, K. G., \& DuFrene, T. (2009). Mindfulness for two: An acceptance and commitment therapy approach to mindfulness in psychotherapy. Oakland, CA: New Harbinger.

Zettle, R. D., \& Hayes, S. C. (1982). Rule governed behavior: A potential theoretical framework for cognitive behavior therapy. In P. C. Kendall (Ed.), Advances in cognitive behavioral research and therapy (pp. 73-118). New York, NY: Academic.

\section{Informações do Artigo}

Histórico do artigo:

Submetido em: 01/Dec/2020

Primeira decisão editorial: 06/Apr/2021

Aceito em: 20/Apr/2021

Editor: William F. Perez 